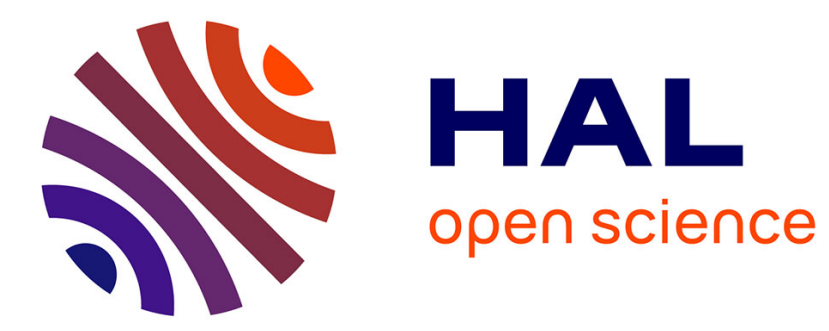

\title{
Effect of chemical and geometrical parameters influencing the wettability of smectite clay films
}

J. Ballah, M. Chamerois, S. Durand-Vidal, N. Malikova, P. Levitz, L.J. Michot

\section{To cite this version:}

J. Ballah, M. Chamerois, S. Durand-Vidal, N. Malikova, P. Levitz, et al.. Effect of chemical and geometrical parameters influencing the wettability of smectite clay films. Colloids and Surfaces A: Physicochemical and Engineering Aspects, 2016, 511, pp.255 - 263. 10.1016/j.colsurfa.2016.10.002 . hal-01386685

\section{HAL Id: hal-01386685 \\ https://hal.sorbonne-universite.fr/hal-01386685}

Submitted on 24 Oct 2016

HAL is a multi-disciplinary open access archive for the deposit and dissemination of scientific research documents, whether they are published or not. The documents may come from teaching and research institutions in France or abroad, or from public or private research centers.
L'archive ouverte pluridisciplinaire HAL, est destinée au dépôt et à la diffusion de documents scientifiques de niveau recherche, publiés ou non, émanant des établissements d'enseignement et de recherche français ou étrangers, des laboratoires publics ou privés. 
Effect of chemical and geometrical parameters influencing the wettability of smectite

clay films

Ballah, $\mathrm{J}^{\mathrm{a}}$., Chamerois, $\mathrm{M}^{\mathrm{b}}$., Durand-Vidal, $\mathrm{S}^{\mathrm{a}}$., Malikova, $\mathrm{N}^{\mathrm{a}}$., Levitz, $\mathrm{P}^{\text {a. }}$, Michot, L.J ${ }^{\mathrm{a}}$ *

${ }^{\text {a }}$ Sorbonne Universités, UPMC Université Paris 06, UMR 8234, PHENIX, 75005 Paris, France

${ }^{\mathrm{b}}$ TOTAL E\&P, Avenue Larribau, 64018, Pau Cedex, France 


\title{
Graphical abstract
}

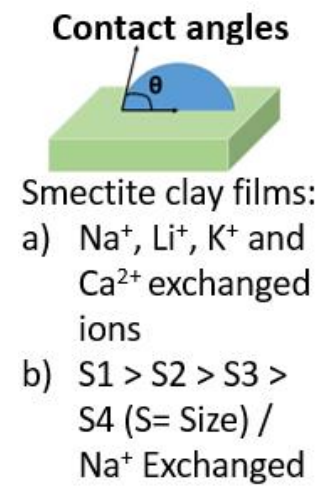

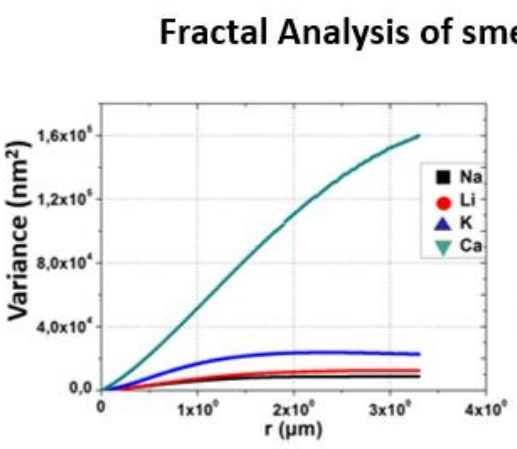

a)

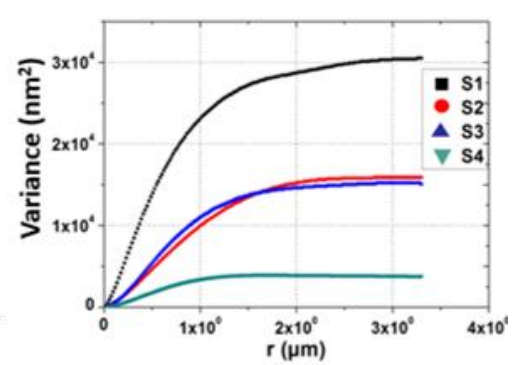

b)

\section{Highlights}

- The influence of exchangeable ions and size of particles on the wettability of clay films is presented.

- In addition to Atomic Force Microscopy parameters, spatial correlation method used to determine the Hurst exponent and the spatial extension of roughness.

- The nature of exchangeable cation influences the roughness of the clay films but it is the hydration energies of the respective cations that mainly control contact angle values.

- For a given exchangeable cation, the size of clay particles influences surface roughness of films and hence contact angles.

- Wettability of clays due to surface ions: efficiency of low salinity waterflooding

\begin{abstract}
The wettability of three swelling clays (beidellite, nontronite and montmorillonite) exchanged with different interlayer ions $\left(\mathrm{Li}^{+}, \mathrm{Na}^{+}, \mathrm{K}^{+}\right.$and $\mathrm{Ca}^{2+}$ ) was investigated by using the static sessile drop method for contact angle measurements. The results show that water contact angles on clay films vary as a function of the nature of the ion with a specific behaviour of $\mathrm{K}^{+}$-exchanged clays. The effect of various parameters influencing contact angle measurements such as relative humidity $(\mathrm{RH})$, particle size and surface roughness has also been examined. RH has only a limited effect on contact angles even if drop stabilisation was observed. As far as the effect of particle size is concerned, the results obtained on montmorillonite of four different sizes show that the smallest angles are obtained on films of particles of the smallest sizes for a given exchangeable ion. This is clearly linked to differences in roughness that were deduced by analysing Atomic Force Microscopy experiments. In contrast, the nature of the exchangeable cation influences roughness in the order $\mathrm{Li}^{+}<\mathrm{Na}^{+}<$ $\mathrm{K}^{+}<\mathrm{Ca}^{2+}$ but this order does not correspond to that deduced from the evolution of contact angles, which confirms the influence of the nature of the cation on wettability.
\end{abstract}


Keywords: Smectites, wettability, contact angle, exchangeable ion, particle size, Hurst exponent.

\section{Introduction}

Wettability is a ubiquitous phenomenon which has attracted much attention and hence led to many publications in the field of chemistry, biology and physics. Basically, wetting is the ability of a liquid to spread, to different extents, on solid surfaces. This ability to spread, is governed by the balance of surface and interfacial forces [1]. Practically, the phenomenon of wettability is exploited in agriculture when sprays are applied to leaves or stalks for a particular treatment, in the textile industry for rain-proofing or providing fire resistance to fibres to cite few examples. Wettability is also of prime importance in the oil industry as the relative oil and water wettability governs the displacement of fluids in reservoirs [2-5]. In that context, it was shown that flooding sandstone reservoirs with low salinity water could result in additional oil yield [68]. However, the mechanisms associated with this technique are not fully understood and all those postulated in the literature are still prone to debate [9]. Most likely, the explanation for additional oil recovery is linked to wettability modifications in sandstone reservoirs. As such, oil is present in the pores of rocks and the injection of low salinity water is believed to displace the oil adsorbed on the walls towards the production wells as a result of wettability modifications. Most literature data converge towards the fact that the presence of clay minerals in the reservoir rock is of prime importance for LSW to be efficient. Understanding clay wettability and its dependence on various parameters is thus of prime importance for a better assessment of this new enhanced oil recovery (EOR) technique.

The present study focuses on clay samples from the smectite group, i.e. beidellite, montmorillonite and nontronite. Though such samples are not the most commonly encountered in reservoirs, they can play a significant role and are also appropriate model minerals for analysing the influence of various physico-chemical parameters. Most clay minerals possess a net charge resulting from the combination of $\mathrm{pH}$ dependent charges and of permanent structural charges. The $\mathrm{pH}$ dependent charges originate from the dangling bonds of silicate groups and the protonation or dissociation of silanols on the clays edges [10]. The role they play in the present study should however be rather marginal. The studied 2:1 smectites (two tetrahedral layers sandwiching an octahedral one), are known to possess surface charges which occur on basal surfaces of the tetrahedral sheets. As far as the permanent structural charges are concerned, they differ from each other by the location of the isomorphic substitutions. Charge deficiency in montmorillonites arises from isomorphic substitutions of $\mathrm{Al}^{3+}$ by $\mathrm{Mg}^{2+}$ in the octahedral sheets whereas for beidellites and nontronites layer charges are located in the tetrahedral sheets due to substitutions of $\mathrm{Si}^{4+}$ by $\mathrm{Al}^{3+}$ and $\mathrm{Fe}^{2+} / \mathrm{Fe}^{3+}$, respectively [11]. Due to these substitutions the platelets are negatively charged, and the resulting negative charge is compensated by exchangeable interlayer cations. It is then interesting and challenging to analyse the role of cation nature on wettability. 
Wettability is commonly assessed by contact angle measurements. When possible, i.e. for smooth and non-porous surfaces, the Static Sessile Drop (SSD) method is well adapted and relatively easy to use. In this technique, a drop of the probed liquid is deposited on the substrate and the contact angle is defined as an equilibrium of the triple phase contact line. In the case of clay materials as those analysed in the present study, this method is more prone to difficulties and the results can strongly vary depending on various parameters such as nature of the surface ions $[\mathbf{1 2 , 1 3}]$, relative humidity $[\mathbf{1 3 , 1 4}]$, particle size $[\mathbf{1 5 , 1 6}]$ and surface roughness $[\mathbf{1 7 - 2 1}]$

As far as the effect of cations nature is concerned, a few studies investigated their influence on wettability. In the case of kaolinite, a non-swelling clay mineral with exchangeable surface ions, Biaeopiotrowicz et al. [12] measured the contact angles of water and diiodomethane on surfaces with $\mathrm{H}^{+}, \mathrm{Na}^{+}, \mathrm{K}^{+}, \mathrm{Ca}^{2+}, \mathrm{Mg}^{2+}, \mathrm{Ba}^{2+}$ and $\mathrm{Al}^{3+}$ counterions. In terms of surface free energy of the different kaolinite samples, their results revealed no major difference of the dispersive components (Van der Waals type force). In contrast, the non-dispersive components (dipoledipole, dipole-induced dipole, hydrogen bonding type forces) increased linearly on clays exchanged with $\mathrm{H}^{+}, \mathrm{Na}^{+}, \mathrm{Ca}^{2+}, \mathrm{Mg}^{2+}$ and $\mathrm{Al}^{3+}$. A linear correlation was thus found between the non-dispersive forces and the respective entropy of hydration of the ions. Both the $\mathrm{K}^{+}$and $\mathrm{Ba}^{2+}$ samples did not follow the obtained linear relationship, which was assigned to the large size of these two ions compared to the other ones. In contrast to these results, Shang et al. [13] observed negligible effect of the nature of surface ions $\left(\mathrm{Na}^{+}, \mathrm{K}^{+}, \mathrm{Mg}^{2+}\right.$ and $\left.\mathrm{Ca}^{2+}\right)$ on water contact angles measured on samples of smectites, kaolinite and illite.

Relative humidity, RH, is an important parameter to be taken into consideration during contact angle measurements. In the interfoliar spacing of smectite clays, water molecules are associated with the interlayer cations. The interaction mechanisms of water molecules with swelling clays can be described according to two main processes [22-24]. At high water content osmotic swelling occurs for smectites with monovalent cations such as $\mathrm{Li}^{+}$or $\mathrm{Na}^{+}$leading to a complete exfoliation of the structure [23, 24]. At lower RH, the hydration capacity of smectites mainly depends on the nature of the interlayer cation $[\mathbf{1 4}, \mathbf{2 5}, \mathbf{2 6}$. Cases et al. and Berend et al. [14, 25] analysed montmorillonite swelling for various interlayer cations and observed an increase in basal spacing with hydration energy according to the following series: $\mathrm{Cs}^{+}<\mathrm{Rb}^{+}<\mathrm{K}^{+}<\mathrm{Na}^{+}$ $<\mathrm{Li}^{+}<\mathrm{Ba}^{2+}<\mathrm{Sr}^{2+}<\mathrm{Ca}^{2+}<\mathrm{Mg}^{2+}$. Consequently the most hydrated clays (hence with the proper exchangeable cations) are expected to give the lowest water contact angles. Concerning contact angles, Shang et al. [13] investigated the effect of relative humidities of 19, 33, 75 and 100\% on smectite, kaolinite and illite with $\mathrm{Ca}^{2+}$ as exchangeable cation. Overall, they did not observe any general trend of the contact angles of water and diiodomethane as a function of $\mathrm{RH}$ at 33 and $75 \%$ but at $100 \%$ RH they recorded a decrease of the contact angles of water and an increase of that of diiodomethane.

The effect of particle size on wettability has to our knowledge not be investigated in the case of clay minerals. Data on the effect of particle size are available for other materials. For instance, Synystka et al. [15] measured dynamic contact angles on hexagonally packed silicon particles of different sizes (containing grafted polymers) and observed that increasing vertical roughness did not modify the advancing angles for particles sizes ranging from 0.2 to $10 \mu \mathrm{m}$. However, the receding contact angles increased until the particles size reached $5 \mu \mathrm{m}$ and then decreased. In their investigations, Yang et al. determined contact angles of molybdenite powders of various sizes by Washburn's method and found that smaller particles exhibited smaller contact angles [16].

Surface roughness is a key parameter influencing contact angle measurements. When a liquid is dropped on a rugged surface, the triple phase contact line is unable to stabilise to a minimum energy [27]. Wenzel, Cassie and Baxter have described models relating contact angles to the 
roughness of surfaces $[\mathbf{2 8 , 2 9 ]}$. Wenzel on his side described the homogeneous wetting regime and stated that upon addition of roughness on a surface, its wettability is enhanced and driven by the chemistry of the surface. For instance, a chemically hydrophobic surface becomes even more hydrophobic provided that the liquid penetrates into the grooves and that the size of the droplet is two to three times larger in magnitude than the roughness. On their side, Cassie and Baxter described the heterogeneous wetting regime where drops bridge across surface protrusions and do not penetrate into the grooves. Whether drops penetrate in grooves (homogeneous wetting regime: Wenzel model) or not (heterogeneous wetting regime with air trapped in between the grooves under the liquid: Cassie-Baxter model), surface roughness plays a key role in determining contact angle values. As far as clay films roughness is concerned, Zabat et al. [30] reported that the nature of the interlayer ions defines the profile of the surface. They studied the roughness of montmorillonite films with various interlayer ions $\mathrm{Li}^{+}, \mathrm{Na}^{+}, \mathrm{Cs}^{+}$, $\mathrm{Mg}^{2+}, \mathrm{Ba}^{2+}, \mathrm{Al}^{3+}$ and $\mathrm{La}^{3+}$ by fractal analysis. The results showed that $h$, the Hurst exponent of fractal Brownian motion, decreased in the order of clays exchanged with monovalent cations to divalent cations and finally to trivalent cations. In short, this indicated that clay films exchanged with monovalent ions are smoother while those with trivalent ions are the roughest ones.

The present study focuses on the effect of various parameters (surface ions, RH, particle size and surface roughness) on the wettability of swelling aluminosilicate clays (the smectites: beidellite, nontronite and montmorillonite). In a first step, the effect of exchangeable ions, $\mathrm{Li}^{+}$, $\mathrm{Na}^{+}$and $\mathrm{Ca}^{2+}$ was analysed on beidellite and Wyoming montmorillonite films and that of $\mathrm{Li}^{+}$, $\mathrm{Na}^{+}, \mathrm{K}^{+}$and $\mathrm{Ca}^{2+}$ on nontronite films using the static sessile drop method under ambient conditions. The effect of humidity on contact angles was then analysed on the different clay samples by working at relative humidity of 84 and $100 \%$ and the results were compared to those obtained under ambient humidity (46\%). Afterwards, films of Arizona montmorillonite of four different sizes exchanged with $\mathrm{Na}^{+}$were probed by AFM to assess the effect of particle size on film roughness and consequently contact angles. Finally, we also investigated the effect of exchangeable ions on the roughness of nontronite films.

\section{Experimental section}

a) Aluminosilicate clay-minerals

The aluminosilicate clay colloids used are: Beidellite (Beid), Wyoming and Arizona Montmorillonites (SWy and SAz respectively), Australia Nontronite (NAu1) obtained from the Source Clay Minerals Repository at Purdue University. Purification procedures and size selection of the clay minerals have then been performed as detailed in references [31, 32]. The sizes were determined by the authors of these papers by performing careful analysis of Transmission Electron Microscopy images. Tables 1 and 2 report the various smectites used with their main morphological features. The average size polydispersity is around 30 to $40 \%$ for all samples.

b) Clay films preparation

Clay films were prepared following the procedure described by $\mathrm{Wu}$ [33]: Microscope glass slides $(2.2 \mathrm{~cm} \times 3.5 \mathrm{~cm})$ were successively cleaned with distilled water and acetone to remove any impurities. $1.5 \mathrm{ml}$ of $3 \mathrm{~g} / \mathrm{L}$ clay suspensions were then deposited on the cleaned glass slides and left to dry at $46 \%$ relative humidity during several hours. 
c) Contact angle measurement

Contact angles measurements for the different films were carried out using the static sessile drop method according to the procedure used by Shang et al. [13]. A similar apparatus as that used by the authors, a DSA100 from Krüss GmbH, Hamburg, Germany, was used. Contact angles on clay films were measured by depositing $5 \mu 1$ water drops dispensed by a $1 \mathrm{ml}$ syringe fitted with steel needle $0.5 \mathrm{~mm}$ in diameter. The temperature recorded at the time of measurement was between 23 and $25^{\circ} \mathrm{C}$. The final contact angle was calculated as a mean on 5 drops.

d) Relative humidity

Measurements were performed either under ambient conditions $(\mathrm{RH} \approx 45 \%)$ or a fixed $\mathrm{RH}$ of 84 and $100 \%$. For these two latter conditions films were equilibrated during 48 hours in air tight transparent plastic boxes containing either a saturated potassium chloride solution or distilled water. The thus reached RH was permanently monitored using a pen-style digital thermohygrometer from VWR. Water contact angles were then measured as a function of time on the different clay samples.

e) Atomic Force Microscopy, AFM

A Nanoscope III multimode scanning probe microscope (Digital Instrument) (TM-AFM) was used in tapping mode to probe the surface of clay films and make images of $(10 \mu \mathrm{m} \times 10 \mu \mathrm{m})$ at a scanning rate of $0.5-0.8 \mathrm{~Hz}$ and a resolution of 512x512. A Phosphorus (n) doped Silicium tip from Veeco used during AFM measurements had a cantilever of resonance frequency of 250 $\mathrm{KHz}$ and spring constant $20-80 \mathrm{~N} / \mathrm{m}$. In order to analyse the effect of particle size and

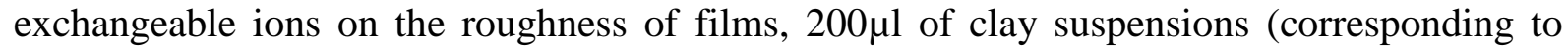
similar clay content per $\mathrm{cm}^{2}$ as films used for contact angle measurements) were deposited on $1 \mathrm{~cm}^{2}$ of pre-cleaned glass slides and left to dry in air before analysis.

\section{Results and discussion}

As an illustration of the obtained results, figures 1a to 1c display the time evolution of contact angles measured for films of Wyoming montmorillonites exchanged with various cations under ambient conditions $(\mathrm{RH}=45 \%)$. Whatever the cation, the measured contact angles significantly decrease with time, which may be assigned to evaporation phenomena that were recently studied in detail [34]. It was decided in the following to focus on the contact angles measured for the shortest times

Table 3 reports the mean contact angles of water drops deposited on clay films under ambient conditions. Considering beidellite, the smallest contact angle was obtained with $\mathrm{Na}^{+}$whereas for both nontronite and montmorilonite, the smallest contact angles was obtained with $\mathrm{Ca}^{2+}$. Even if the case of $\mathrm{K}^{+}$was only analysed for nontronite, it displays the highest values of all the tested materials. In the series of analysed monovalent ions, $\mathrm{K}^{+}$is the least hydrated (the standard ion hydration enthalpies $\Delta_{\text {hyd }} \mathrm{H}_{\text {of }} \mathrm{Li}^{+}, \mathrm{Na}^{+}$and $\mathrm{K}^{+}$are $-520,-405$ and $-321 \mathrm{~kJ} / \mathrm{mole}$ respectively [35]). These hydration energies are linked to the charge densities (charge/ionic radius ratio) of the ions that decrease in the order of $\mathrm{Li}^{+}, \mathrm{Na}^{+}$and $\mathrm{K}^{+}$and, naturally, are followed by a decrease of the affinity for water molecules. This is partly revealed by the contact angle on the $\mathrm{K}^{+}$sample which is the highest among the three. However, the results obtained with $\mathrm{Na}^{+}$and $\mathrm{Li}^{+}$are not always consistent with that sequence, a feature that will be discussed later on. As far as $\mathrm{Ca}^{2+}$ is concerned, having the highest charge density and the most favourable hydration energy $\left(\Delta_{\text {hyd }} \mathrm{H}\right.$ of $\mathrm{Ca}^{2+}=-1650 \mathrm{~kJ} / \mathrm{mole}$ [35]), the corresponding exchanged clays are expected to have the smallest contact angles. In order to investigate if, as indicated by these first measurements, $\mathrm{K}^{+}$, 
due to its low hydration enthalpy actually leads to higher contact angles, additional experiments with concentrated chloride solutions, instead of water, were performed. As shown in Table 4, they clearly reveal that the presence of $\mathrm{K}^{+}$ions generates higher contact angles than any of the other ions used in the present study. The differences thus observed are of higher magnitude that what would be expected on the basis of surface tension differences at the air/electrolyte interface [36].

Effect of Relative humidity: In the case of swelling clay minerals, the role of relative humidity (RH) may be particularly important in view of the specific interactions between water and these minerals and considering the evaporation phenomena mentioned earlier. Furthermore, the way according to which clay hydrates strongly depend on the nature of the interlayer cations and different results could be obtained for different cations. The first effect of increased RH can be seen from the curves displayed in Figure 2 (Wyoming Montmorillonite exchanged with $\mathrm{Li}^{+}$, $\mathrm{Na}^{+}$and $\mathrm{Ca}^{2+}$ ) that exhibit the time evolution of contact angles. Indeed, compared to the curves obtained in Figure 1, high RH leads to a stabilisation of the contact angle at long times, which was not the case at $45 \% \mathrm{RH}$ where a linear decrease was observed. This can be attributed to a strong decrease in evaporation. Still, if one considers the values obtained at short times, RH marginally modifies the contact angles measured for samples exchanged with $\mathrm{Na}^{+}$and $\mathrm{Li}^{+}$that display a slight decrease, in agreement with previous results, whereas it does not seem to have any effect for the $\mathrm{Ca}^{2+}$-exchanged system. This can tentatively be assigned to the difference in hydration between these cations. Indeed, for $\mathrm{Na}^{+}$and $\mathrm{Li}^{+}$, upon an increase in $\mathrm{RH}$ from $46 \%$ to $84 \%$, the samples evolve from a situation where the dominant hydration state is a one-layer one to a situation where the two-layer hydrates dominates $[\mathbf{2 5}, \mathbf{3 7}])$. This is not the case for $\mathrm{Ca}^{2+}$ where at $45 \% \mathrm{RH}$, most layers are already in a two-layer hydrate state [37].

Finally, at high RH, the fact that a plateau is observed at long times may indicate that some equilibrium can be reached in such conditions, whereas this is not the case for lower RH. It is then relevant to compare the values obtained at the plateau that can be referred to as stabilised values (Table 5). This table reveals once more the specific role of $\mathrm{K}^{+}$as clays exchanged with this cation display significantly higher contact angles.

Particle size: The effect of particle size on contact angles was investigated on samples of four different sizes of Arizona montmorillonite with $\mathrm{Na}^{+}$as exchangeable cation. The results shown in Table 6 indicate that the film composed of particles with the largest size (S1) has the largest contact angle while that composed of particles of the smallest size (S4) displays the smallest contact angle. The average individual particle size in the films therefore appears to affect contact angles. As the physico-chemical characteristics of the particles are independent of size [32], such an effect could be due to difference in roughness of the different films investigated.

Film roughness: The films of Arizona montmorillonite exchanged with $\mathrm{Na}^{+}$were probed by AFM and Table 5 displays some of the parameters deduced from the images, i.e. the $2 \mathrm{D}$ and $3 \mathrm{D}$ image surface areas, the root mean square (RMS) of heights and $\mathrm{R}_{\max }$. The difference in image surface area corresponds to the difference between the image's three-dimensional surface area and its two-dimensional footprint. The RMS is the root mean square average of the height deviations $(Z)$ taken from the mean data plane $\left(R M S=\sqrt{\frac{\sum Z_{i}^{2}}{n}}\right) . \mathrm{R}_{\max }$ corresponds to the maximum vertical distance between the highest and the lowest data points in the image. For a clearer insight, the RMS and $\mathrm{R}_{\max }$ are shown in Figure 3 below. The values of these parameters 
clearly yield three groups correlated to the contact angle values: Particles S1 with high roughness and higher contact angles, particles S2 and S3 with medium contact angles and roughness parameters, and particles $\mathrm{S} 4$ with lower values for both parameters.

For instance, films of montmorillonite exchanged with $\mathrm{Na}^{+}$but made up of particles of different sizes clearly indicate that roughness significantly impacts contact angle values, as there is a direct correlation between roughness indicators and contact angles. In terms of roughness analysis, it is possible to obtain further data on the spatial correlation of roughness. To reach such a goal, correlation of heights was performed in such a way that local information is conserved as the distance is increased from a statistical origin. This can be achieved by estimating the variogram, $\mathrm{V}$, of the heights $Z$, between 2 points situated at $r_{2 D}^{\prime}$ and $r_{2 D}$ averaged on $r_{2 D}^{\prime}$ as follows:

$V\left(\vec{r}_{2 D}\right)=\left\langle\left(z\left(\vec{r}_{2 D}^{\prime}+\vec{r}_{2 D}\right)-z\left({\overrightarrow{r^{\prime}}}_{2 D}\right)\right)^{2}\right\rangle_{\vec{r}_{2 D}} \quad$ Eq.1

For isotropic images, the morphology is statistically invariant along the axes $(x, y)$ and the variance is an angular average. Consequently :

$V(r)=\left\langle V\left(\vec{r}_{2 D}\right)\right\rangle_{2 \pi}$

Eq.2

In the case of self-affine fractal surfaces it can be shown that the variogram can be written as [38] :

$V(r) \propto r^{2 h} \quad$ Eq.3

with the fractal dimension, $\bar{d}=3-h$, where $h$ is the Hurst exponent that varies between 0 for rough surfaces and 1 for smooth surfaces.

Figure 3 displays the variance of heights versus correlation length for the 4 films previously described. In parallel, table 7 reports the different parameters that can be deduced from such an analysis, i.e. $h$ the Hurst exponent derived from the first linear part of the curves, the variance at plateau indicating the maximum variance recorded between 2 heights and $r$ the correlation length at which the variance reaches an horizontal plateau and beyond which the sample can be considered as smooth. For small correlation lengths, the $h$ exponent is similar for the 4 particle sizes. In contrast, both the variance at the plateau and the $r$ value corresponding to the beginning of the plateau evolve with particle size in similar ways as that observed for the non spatialized parameters (Table 6), i.e. S4 $<\mathrm{S} 3 \approx \mathrm{S} 2<\mathrm{S} 1$. These results clearly indicate that the film formed with the largest particles (S1) exhibits higher peaks and requires a longer dimension in the horizontal (x, y) plane to be regarded as smooth. This latter dimension described by the parameter $r$ is $3.4 \mu \mathrm{m}$, which corresponds to about 11 clay platelets laid side by side. Upon decreasing particle size, $r$ decreases and for the smallest particles it corresponds to around 32 clay platelets. 
Both types of analyses confirm the close relationship between contact angles and surface roughness and reveal that this latter parameter is of prime importance. Considering this result, it is particularly relevant to analyse the surface roughness of the films previously described exchanged with various cations. Indeed, this will allow determining if the specific behaviour of $\mathrm{K}^{+}$previously evidenced results from physical chemistry reasons or from significant changes in film roughness.

Exchangeable cations and surface roughness: Table 8 reports the contact angles measured for nontronite particles exchanged with $\mathrm{Li}^{+}, \mathrm{Na}^{+}, \mathrm{K}^{+}$and $\mathrm{Ca}^{2+}$ together with the roughness parameters deduced from both the classical and fractal analysis. All roughness indicators point towards the following order of increasing surface roughness $\mathrm{Na}^{+}<\mathrm{Li}^{+}<\mathrm{K}^{+}<<\mathrm{Ca}^{2+}$. All films exhibit the same Hurst exponent around 0.7 except those based on $\mathrm{Ca}$-exchanged nontronite for which the Hurst exponent is significantly lower at 0.6. Furthermore the $\mathrm{Ca}^{2+}$ based films are much rougher than all the other ones (Figure 4). That difference between monovalent and divalent cations can be tentatively assigned to the nature of the particles in the suspension. Indeed, for all monovalent cations, delaminated suspensions are obtained whereas in the $\mathrm{Ca}^{2+}$ case, particles formed with a few layers are present $[39,40]$. For instance, accordingly to the Hofmeister series, highly hydrated monovalent $\mathrm{Li}^{+}$and $\mathrm{Na}^{+}$counterions are only weakly or not at all adsorbed on clay surfaces, thus maintaining a stable and evenly dispersed clay platelet suspension. The $\mathrm{K}^{+}$counterions, less hydrated than the previous cations, show a higher affinity for the negatively charged clay platelets than the previous cations. As far as the divalent $\mathrm{Ca}^{2+}$ ions are concerned, despite their high hydration energies, they primarily follow the SchulzeHardy rule and result in particle aggregation and very rough surfaces $[\mathbf{4 1 , 4 2 , 4 3 ] .}$

The direct relationship between contact angles and roughness observed for particles of various sizes does not hold here as the roughest film also exhibits the lowest contact angle. Rather, the situation is in agreement with the model of Wenzel where the chemistry of the surface governs the measured contact angle. For instance, $\mathrm{Ca}^{2+}$ ions possess the most favourable hydration enthalpy and surface roughness of NAu1- $\mathrm{Ca}^{2+}$ film being the highest, the hydrophilic character is enhanced and hence resulted in the lowest contact angle. On the other hand, the NAul- $\mathrm{K}^{+}$ film possess intermediate roughness among the analysed series and possess the highest contact angle essentially driven by the chemistry of the surface (low free hydration energy).

\section{Conclusion}

The influence of various parameters (nature of exchangeable cations, relative humidity, particle size and surface roughness) on clay wettability has been studied. Even though these parameters have been investigated individually, the nature of cations, particle size and surface roughness are closely linked. As such, detailed analysis of AFM images has shown that for a given clay mineral, exchanged with a given cation, the wettability of the film is influenced by the size of the particles. For instance, the larger the size of the clay platelets, the rougher the film. As far as the effect of the nature of exchangeable cation is concerned, clay films of similar particle size show that the wettability of the swelling clays is a priori 
driven by the hydration energies of the ions. Indeed, the water contact angles on clay films of the different exchangeable cations are in agreement with their respective hydration energies. However, even if initially the nature of the exchangeable ions has shown to influence the roughness of the clay films $\left(\mathrm{Ca}^{2+}>>\mathrm{K}^{+}>\mathrm{Li}^{+}>\mathrm{Na}^{+}\right)$, ultimately it's the hydration energy which takes over, as pretty well illustrated by the case of $\mathrm{K}^{+}$and $\mathrm{Ca}^{2+}$. Finally, relative humidity only has a marginal effect on contact angle values but modifies the time evolution of contact angle that are more stable at high relative humidity. On the basis of the different results obtained, the exchangeable cations have shown to be a key aspect of clays wettability and could therefore act as an important feature in various applications such as low salinity waterflooding. Still, more work is required in order to understand the basis of this EOR technique.

Funding: The financial support for this work was provided by TOTAL (grant number FR00006794, 2013-2016].

\section{References}

1. Abdallah, W., Buckley, J. S., Carnegie, A., Edwards, J., Herold, B., Fordham, E. \& Hussain, H. (1986). Fundamentals of wettability. Technology, 38(1125-1144), 268.

2. Anderson, W. G. (1987). Wettability literature survey-part 4: Effects of wettability on capillary pressure. Journal of Petroleum Technology, 39(10), 1-283.

3. Anderson, W. G. (1987). Wettability literature survey part 5: the effects of wettability on relative permeability. Journal of Petroleum Technology, 39(11), 1-453.

4. Morrow, N. R. (1990). Wettability and its effect on oil recovery. Journal of Petroleum Technology, 42(12), 1-476.

5. Jadhunandan, P. P., \& Morrow, N. R. (1995). Effect of wettability on waterflood recovery for crudeoil/brine/rock systems. SPE reservoir engineering, 10(01), 40-46.

6. Tang, G. Q., \& Morrow, N. R. (1997). Salinity, temperature, oil composition, and oil recovery by waterflooding. SPE Reservoir Engineering, 12(04), 269276.

7. Webb, K. J., Black, C. J. J., \& Al-Ajeel, H. (2004). Low Salinity Oil Recovery-Log-Inject-Log. Paper SPE 89379, SPE. In DOE Symposium on Improved Oil Recovery, Oklahoma.

8. McGuire, P. L., Chatham, J. R., Paskvan, F. K., Sommer, D. M., \& Carini, F. H. (2005). Low salinity oil recovery: An exciting new EOR opportunity for Alaska's North Slope. In SPE Western Regional Meeting. Society of Petroleum Engineers.

9. Soraya, B., Malick, C., Philippe, C., Bertin, H. J., \& Hamon, G. (2009). Oil recovery by low-salinity brine injection: Laboratory results on outcrop and reservoir cores. In SPE Annual Technical Conference and Exhibition. Society of Petroleum Engineers.

10. McBride, M. B. (1994). Environmental chemistry of soils. Oxford university press.

11. Ross, C. S., \& Hendricks, S. B. (1945). Minerals of the montmorillonite group, their origin and relation to soils and clays (No. 205-B). 
12. Biaeopiotrowicz, T., \& Stawrinsk, J. (1989). Influence of exchangeable cations on the surface free energy of kaolinite as determined from contact angles. Clays and Clay Minerals, 37(3), 269-272.

13. Shang, J., Flury, M., Harsh, J. B., \& Zollars, R. L. (2010). Contact angles of aluminosilicate clays as affected by relative humidity and exchangeable cations. Colloids and Surfaces A: Physicochemical and Engineering Aspects, 353(1), 1-9.

14. Cases, J. M., Bérend, I., François, M., Uriot, J. P., Michot, L. J., \& Thomas, F. (1997). Mechanism of adsorption and desorption of water vapor by homoionic montmorillonite; 3 , The $\mathrm{Mg}^{2+}, \mathrm{Ca}^{2+}, \mathrm{Sr}^{2+}$, and $\mathrm{Ba}^{2+}$ exchanged forms. Clays and Clay Minerals, 45(1), 8-22.

15. Synytska, A., Ionov, L., Minko, S., Motornov, M., Elchorn, K., Stamm, M., \& Grundke, K. (2004). Tuning wettability by controlled roughness and surface modification using core-shell particles. Polym Mater Sci Eng, 90, 624-625.

16. Yang, B., Song, S., \& Lopez-Valdivieso, A. (2014). Effect of particle size on the contact angle of molybdenite powders. Mineral Processing and Extractive Metallurgy Review, 35(3), 208-215.

17. Oliver, J. P., Huh, C., \& Mason, S. G. (1980). An experimental study of some effects of solid surface roughness on wetting. Colloids and Surfaces, 1(1), 79-104.

18. Drelich, J., Miller, J. D., \& Good, R. J. (1996). The effect of drop (bubble) size on advancing and receding contact angles for heterogeneous and rough solid surfaces as observed with sessile-drop and captive-bubble techniques. Journal of Colloid and Interface Science, 179(1), 37-50.

19. Shibuichi, S., Yamamoto, T., Onda, T., \& Tsujii, K. (1998). Super water-and oil-repellent surfaces resulting from fractal structure. Journal of Colloid and Interface Science, 208(1), 287-294.

20. Chen, W., Fadeev, A. Y., Hsieh, M. C., Öner, D., Youngblood, J., \& McCarthy, T. J. (1999). Ultrahydrophobic and ultralyophobic surfaces: some comments and examples. Langmuir, 15(10), 3395-3399.

21. Miwa, M., Nakajima, A., Fujishima, A., Hashimoto, K., \& Watanabe, T. (2000). Effects of the surface roughness on sliding angles of water droplets on superhydrophobic surfaces. Langmuir, 16(13), 5754-5760.

22. Norrish, K. (1954). The swelling of montmorillonite. Discussions of the Faraday society, 18, 120134.

23. Michot, L.J., Bihannic, I., Maddi, S., Baravian, C., Levitz, P., Davidson, P. (2008) Sol-Gel and Isotropic/nematic transitions in aqueous suspensions of natural nontronite clay. Influence of particle anisotropy. Part 1. Features of the I/N transition Langmuir, 24, 3127-3139.

24. Michot, L.J., Bihannic, I., Maddi, S., Duval, J.F.L., Baravian, C., Moyne, C., Levitz, P., Davidson, P. (2009) Sol-Gel and Isotropic/nematic transitions in aqueous suspensions of natural nontronite clay. Influence of particle anisotropy. Part 2. Gel structure and Rheology Langmuir, 25, 127-139.

25. Bérend, I., Cases, J.M., François, M., Uriot, J.P., Michot, L.J., Masion, A., Thomas, F. (1995)

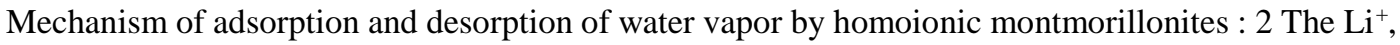
$\mathrm{Na}^{+}, \mathrm{K}^{+}, \mathrm{Rb}^{+}$and $\mathrm{Cs}^{+}$exchanged forms. Clays and Clay Minerals, 43,3, 324-336

26. Xu, W., Johnston, C. T., Parker, P., \& Agnew, S. F. (2000). Infrared study of water sorption on Na-, Li-, Ca-, and Mg-exchanged (SWy-1 \& SAz-1) montmorillonite. Clays and Clay Minerals, 48(1), $120-131$.

27. Della Volpe, C., Maniglio, D., Morra, M., \& Siboni, S. (2002). The determination of a 'stableequilibrium'contact angle on heterogeneous and rough surfaces. Colloids and Surfaces A: Physicochemical and Engineering Aspects, 206(1), 47-67.

28. Wenzel, R. N. (1936). Resistance of solid surfaces to wetting by water. Industrial \& Engineering Chemistry, 28(8), 988-994. 
29. Cassie, A. B. D., \& Baxter, S. (1944). Wettability of porous surfaces. Transactions of the Faraday Society, 40, 546-551.

30. Zabat, M., Harba, R., \& Van Damme, H. (2015). Fractal analysis of surface roughness of montmorillonite clay self-supported films: Effects of exchanged cations and of mechanical tensile stress. Colloids and Surfaces A: Physicochemical and Engineering Aspects, 486, 38-44.

31. Michot, L. J., Bihannic, I., Porsch, K., Maddi, S., Baravian, C., Mougel, J., \& Levitz, P. (2004). Phase diagrams of Wyoming Na-montmorillonite clay. Influence of particle anisotropy. Langmuir, 20(25), 10829-10837.

32. Paineau, E., Bihannic, I., Baravian, C., Philippe, A. M., Davidson, P., Levitz, P., ... \& Michot, L. J. (2011). Aqueous suspensions of natural swelling clay minerals. 1. Structure and electrostatic interactions. Langmuir, 27(9), 5562-5573.

33. Wu, W. (2001). Baseline studies of the clay minerals society source clays: colloid and surface phenomena. Clays and Clay Minerals, 49(5), 446-452.

34. Soulié, V., Karpitschka, S., Lequien, F., Prené, P, Zemb, T., Moehwald, H. \& Riegler, H. (2015). The evaporation behaviour of sessile droplets from aqueous saline solutions. Physical Chemistry Chemical Physics, 17, 22296-22303.

35. Bockris J.O’M. and Reddy A.K.N. (1970), Modern Electrochemistry, Vol 1, Plenum Press, New Yolk.

36. Aveyard, R., \& Saleem, S. M. (1976). Interfacial tensions at alkane-aqueous electrolyte interfaces. Journal of the Chemical Society, Faraday Transactions 1: Physical Chemistry in Condensed Phases, 72, 1609-1617.

37. Ferrage, E., Lanson, B., Sakharov, B, \& Drits, V.A. (2005) Investigation of smectite hydration properties by modeling experimental X-ray diffraction patterns: Part I. Montmorillonite hydration properties. American Mineralogist, 90, 1358-1374.

38. Barnsley, M.F., Devaney, R.L., Mandelbrot, B.B., Peitgen, H-O., Saupe, D. \& Voss, R.F. (1999) The Science of Fractal Images. Peitgen, H-O. and Saupe, D. eds. Springer-Verlag, New Yolk.

39. Schramm, L.L and Kwak, J.C.T. (1982) Influence of exchangeable cation compositions on the size and shape of montmorillonite particles in dilute suspension. Clays and Clay Minerals, 30, 40-48.

40. Segad, M., Hanski, S., Olsson, U., Ruokolainen, J., Akesson, T., \& Jonsson, B. (2012) Microstructural and Swelling Properties of $\mathrm{Ca}$ and $\mathrm{Na}$ Montmorillonite: (In Situ) Observations with Cryo-TEM and SAXS. Journal of Physical Chemistry C, 116, 7596-7601.

41. Schwierz, N., Horinek, D., \& Netz, R. R. (2010). Reversed anionic Hofmeister series: the interplay of surface charge and surface polarity. Langmuir, 26(10), 7370-7379.

42. Oncsik, T., Trefalt, G., Borkovec, M., \& Szilagyi, I. (2015). Specific ion effects on particle aggregation induced by monovalent salts within the Hofmeister series. Langmuir, 31(13), 3799-3807.

43. Pavlovic, M., Huber, R., Adok-Sipiczki, M., Nardin, C., \& Szilagyi, I. (2016). Ion specific effects on the stability of layered double hydroxide colloids. Soft matter, 12(17), 4024-4033. 


\section{Contact Angles as a function of the different interlayer ions:}

a)

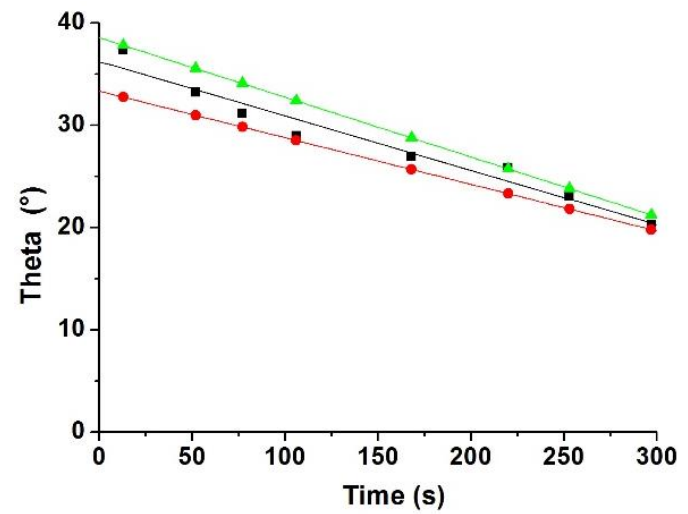

b)
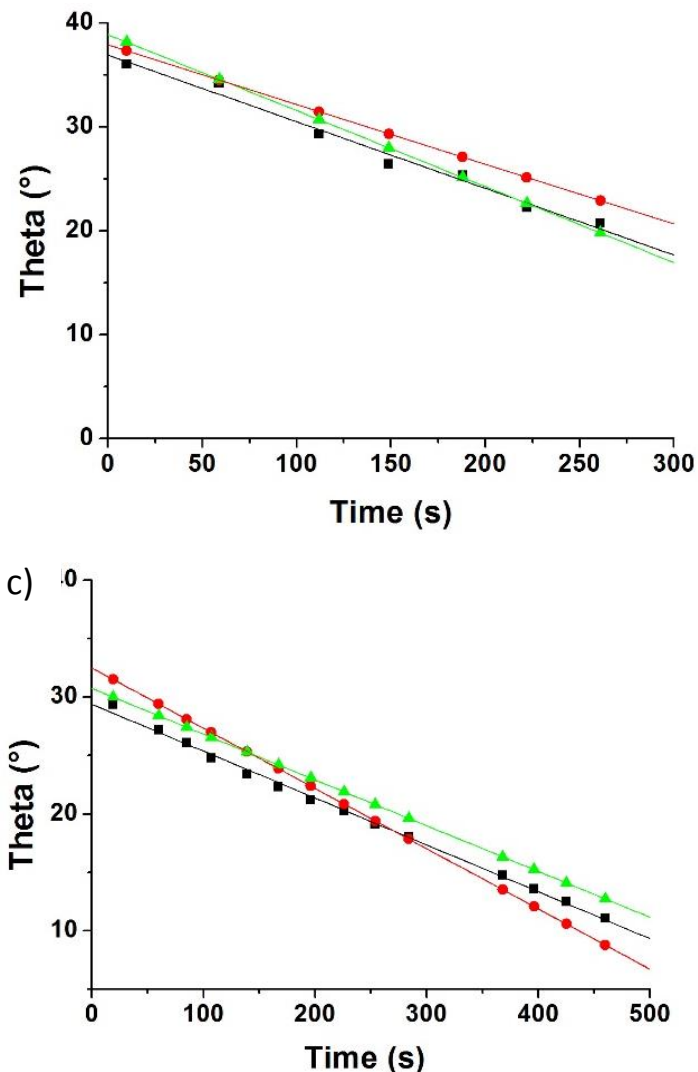

Figures $1 \mathrm{a}, 1 \mathrm{~b}$, and $1 \mathrm{c}$ respectively show the contact angles $\left(^{\circ}\right)$ of different drops on each sample as a function of time of: $\mathrm{SWy}-\mathrm{Li}^{+}, \mathrm{SWy}-\mathrm{Na}^{+}$and $\mathrm{SWy}-\mathrm{Ca}^{2+}$ at $\mathrm{RH}=45 \%$. 

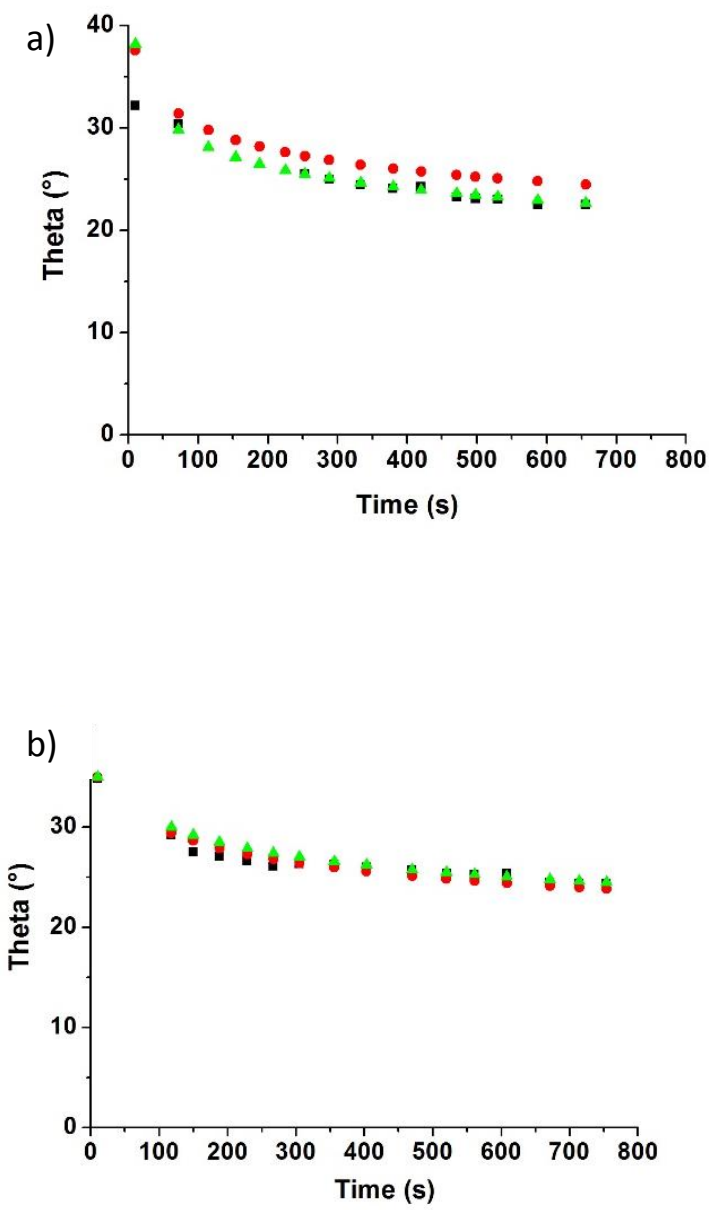

${ }^{4}$ c)

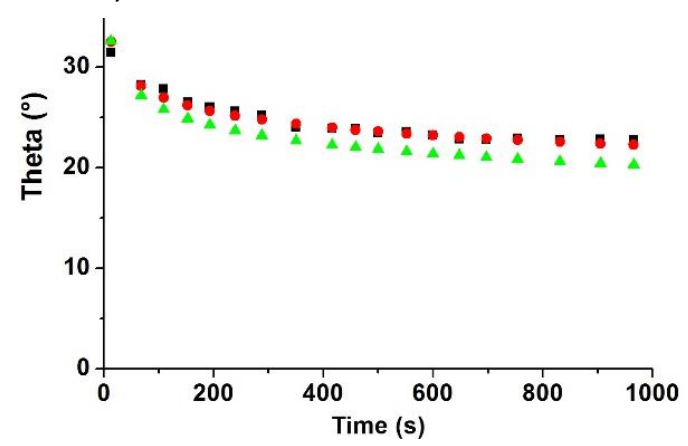

Figures $2 \mathrm{a}, 2 \mathrm{~b}$ and $2 \mathrm{c}$ respectively show the contact angles $\left({ }^{\circ}\right)$ of different drops as a function of time on samples of: $\mathrm{SWy}-\mathrm{Li}^{+}, \mathrm{SWy}_{-} \mathrm{Na}^{+}$and $\mathrm{SWy}-\mathrm{Ca}^{2+}$ at $\mathrm{RH}=100 \%$. 


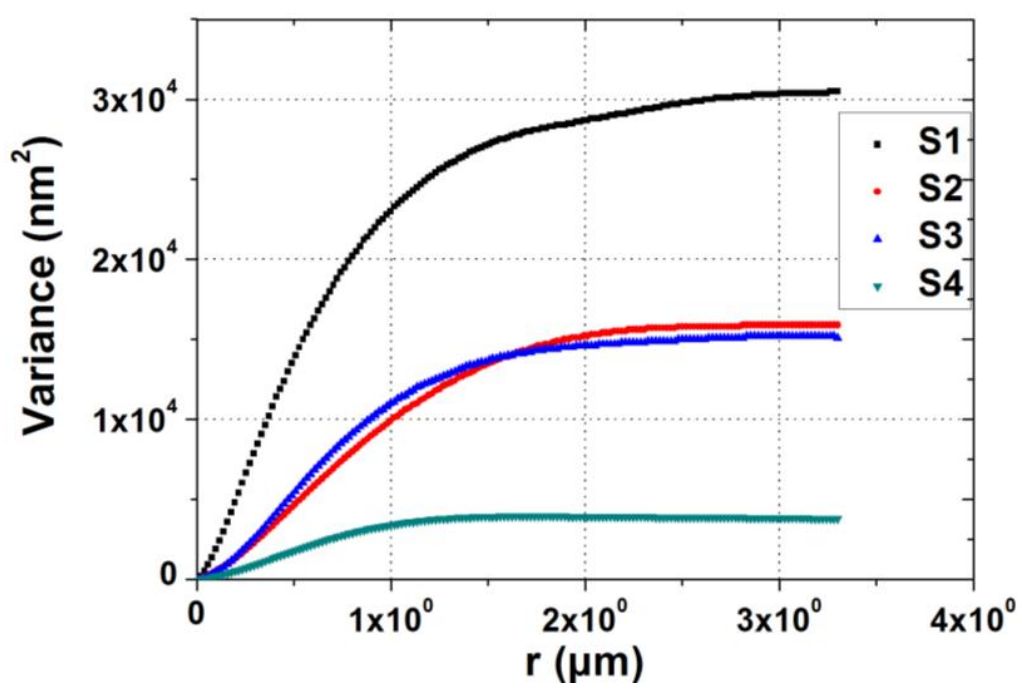

Figure 3: Variance of heights on films of particles S1, S2, S3 and S4 with respect to the correlation lengths. 


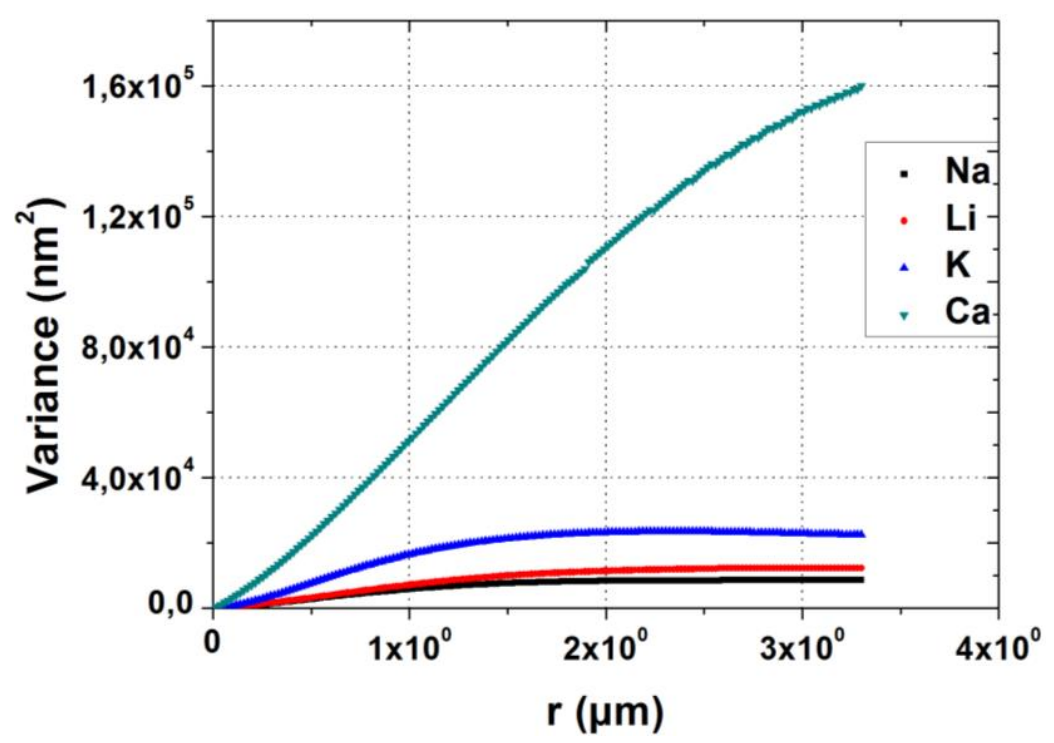

Figure 4: Variance of heights on films of particles with $\mathrm{Na}^{+}, \mathrm{Li}^{+}, \mathrm{K}^{+}$and $\mathrm{Ca}^{2+}$ with respect to the correlation lengths. 

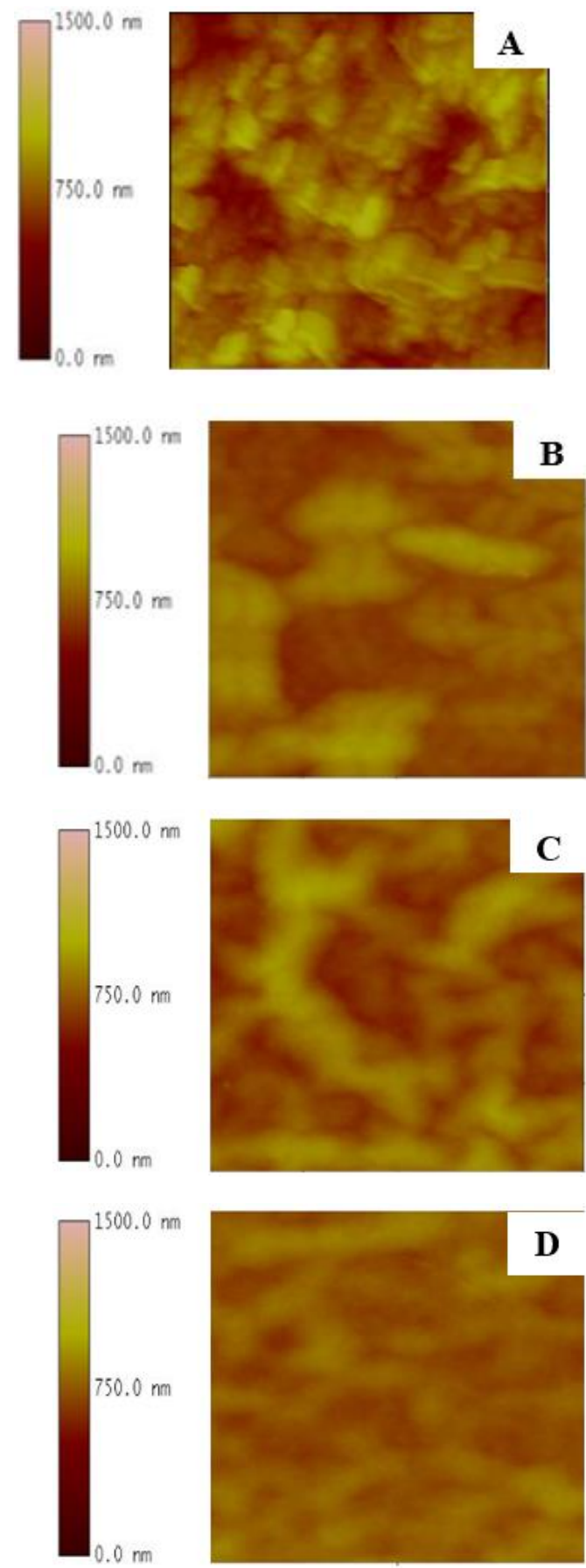

Image 1: (10x10) $\mu \mathrm{m}$ AFM of Arizona montmorillonte exchanged with $\mathrm{Na}^{+}$films. (A) is $\mathrm{S} 1$ film. (B) is $\mathrm{S} 2$ film. (C) is S3 film and (D) is S4 film. Contrasts linked to the topography of the films appear as bright zones corresponding to higher altitudes while those situated in depth appear as dark zones 


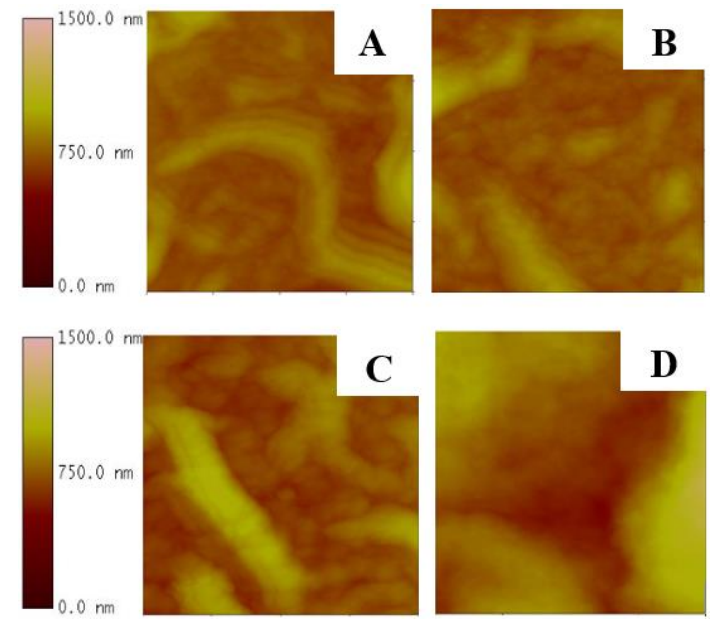

Image 2: (10x10) $\mu \mathrm{m}$ AFM of clay films. (A) is $\mathrm{Li}^{+}$film. (B) is $\mathrm{Na}^{+}$film. (C) is $\mathrm{K}^{+}$film and (D) is $\mathrm{Ca}^{2+}$ film. Contrasts linked to the topography of the films appear as bright zones corresponding to higher altitudes while those situated in depth appear as dark zones 
Table 1: The different swelling clays, exchangeable cations, particles shapes and average sizes used in the study

\begin{tabular}{|c|c|c|}
\hline Clay mineral & $\begin{array}{l}\text { Interlayer } \\
\text { ion }\end{array}$ & $\begin{array}{l}\text { Particle shape } \\
\text { and average } \\
\text { size }(\mathrm{nm})\end{array}$ \\
\hline Beidellite (Beid) & $\begin{array}{ll}\mathrm{Li}^{+}, & \mathrm{Na}^{+}, \\
\mathrm{Ca}^{2+} & \\
\end{array}$ & $\begin{array}{l}\text { Discs of } 400 \\
\text { (in diameter) }\end{array}$ \\
\hline $\begin{array}{l}\text { Wyoming } \\
\text { Montmorillonite } \\
(\mathrm{SWy})\end{array}$ & $\begin{array}{ll}\mathrm{Li}^{+}, & \mathrm{Na}^{+}, \\
\mathrm{Ca}^{2+} & \end{array}$ & $\begin{array}{l}\text { Discs of } 250 \\
\text { (in diameter) }\end{array}$ \\
\hline $\begin{array}{l}\text { Nontronite } \\
\text { (NAu1) }\end{array}$ & $\begin{array}{l}\mathrm{Li}^{+}, \mathrm{Na}^{+}, \mathrm{K}^{+}, \\
\mathrm{Ca}^{2+}\end{array}$ & $\begin{array}{l}\text { Laths } \\
(200 \times 700)\end{array}$ \\
\hline
\end{tabular}


Table 2: Average sizes of Arizona Montmorillonite exchanged with $\mathrm{Na}^{+}$cation used in the study.

Discs of Arizona Montmorillonite (SAz)-

Exchanged with $\mathrm{Na}^{+}$ions

Size 1: S1

$300 \mathrm{~nm}$

Size 2: S2

$150 \mathrm{~nm}$

Size 3: S3

$95 \mathrm{~nm}$

Size 4: S4

$40 \mathrm{~nm}$ 
Table 3: Water contact angles $\left( \pm 3-5^{\circ}\right)$ measured on the different clays containing $\mathrm{Li}^{+}, \mathrm{Na}^{+}, \mathrm{K}^{+}$and $\mathrm{Ca}^{2+}$ as exchangeable ion at $45 \% \mathrm{RH}$.

\begin{tabular}{l|cccc}
\multirow{2}{*}{$\begin{array}{l}\text { Clay } \\
\text { mineral }\end{array}$} & \multicolumn{3}{|l}{ Interlayer ion } & \\
\cline { 2 - 5 } & $\mathrm{Li}^{+}$ & $\mathrm{Na}^{+}$ & $\mathrm{K}^{+}$ & $\mathrm{Ca}^{2+}$ \\
\hline Beid & 29 & 17 & - & 26 \\
NAu1 & 40 & 30 & 50 & 21 \\
SWy & 37 & 38 & - & 31 \\
\hline
\end{tabular}


Table 4: Contact angles $\left( \pm 3-5^{\circ}\right)$ of different probed liquids measured on NAu1 films containing $\mathrm{Li}^{+}, \mathrm{Na}^{+}, \mathrm{K}^{+}$and $\mathrm{Ca}^{2+}$ as exchangeable ion.

\begin{tabular}{l|cccc} 
& \multicolumn{4}{|l}{ Interlayer ion } \\
$\begin{array}{l}\text { Probed } \\
\text { Liquid and } \\
\text { concentration }\end{array}$ & $\mathrm{Li}^{+}$ & $\mathrm{Na}^{+}$ & $\mathrm{K}^{+}$ & $\mathrm{Ca}^{2+}$ \\
\hline $\mathrm{NaCl}(1 \mathrm{M})$ & 26 & 21 & $\mathbf{2 9}$ & 28 \\
$\mathrm{KCl}(1 \mathrm{M})$ & $\mathbf{3 5}$ & $\mathbf{3 6}$ & $\mathbf{3 8}$ & $\mathbf{4 2}$ \\
$\mathrm{CaCl}_{2}(0.5 \mathrm{M})$ & 25 & 22 & $\mathbf{2 9}$ & 27 \\
$\mathrm{MgCl}_{2}(0.5 \mathrm{M})$ & 19 & 19 & $\mathbf{2 7}$ & 22 \\
\hline
\end{tabular}


Table 5: Mean stabilised water contact angles $\left( \pm 3-5^{\circ}\right)$ recorded on beidellite, nontronite and montmorillonite films at relative humidities of 84 and $100 \%$

\begin{tabular}{|c|c|c|c|c|c|}
\hline \multirow{2}{*}{ Clay mineral } & \multirow{2}{*}{$\begin{array}{l}\text { Relative Humidity, RH, } \\
(\%)\end{array}$} & \multicolumn{4}{|c|}{ Interlayer ion } \\
\hline & & $\mathrm{Li}^{+}$ & $\mathrm{Na}^{+}$ & $\mathrm{K}^{+}$ & $\mathrm{Ca}^{2+}$ \\
\hline \multirow{2}{*}{ Beid } & 84 & 17 & 13 & - & 21 \\
\hline & 100 & 15 & 15 & - & 20 \\
\hline \multirow[t]{2}{*}{ NAu1 } & 84 & 23 & 20 & 45 & 21 \\
\hline & 100 & 23 & 20 & 43 & 21 \\
\hline \multirow[t]{2}{*}{ SWy } & 84 & 20 & 23 & - & 25 \\
\hline & 100 & 23 & 23 & - & 23 \\
\hline
\end{tabular}


Table 6: Contact angles and mean roughness parameters calculated on 4 images of each films composed of particles of sizes S1, S2, S3 and S4

\begin{tabular}{l|llll} 
Particle Size & $\mathrm{S} 1$ & $\mathrm{~S} 2$ & $\mathrm{~S} 3$ & $\mathrm{~S} 4$ \\
\hline Contact Angle at 45\% $\mathrm{RH} /{ }^{\circ}$ & 38 & 31 & 28 & 20 \\
Image 2D surface area / $\mu \mathrm{m}^{2}$ & 100 & 100 & 100 & 100 \\
Image 3D surface area / $\mu \mathrm{m}^{2}$ & 115.5 & 104.7 & 104.7 & 102.9 \\
Image surface area difference / \% & 15.5 & 4.70 & 4,66 & 2.90 \\
$\mathrm{RMS} / \mathrm{nm}$ & 118.3 & 85.3 & 82.26 & 43.5 \\
$\mathrm{R}_{\max } / \mathrm{nm}$ & 764.7 & 467.6 & 454.17 & 251.9 \\
\hline
\end{tabular}


Table 7: Fractal analysis parameters on films made up of particles of size S1, S2, S3 and S4.

\begin{tabular}{l|lll}
$\begin{array}{l}\text { Particle } \\
\text { size }\end{array}$ & $H$ & $\begin{array}{l}\text { Variance } \\
\text { plateau }\left(\mathrm{nm}^{2}\right)\end{array}$ & at \\
\hline S1 & 0.68 & 30000 & 3.0 \\
S2 & 0.65 & 15800 & 2.3 \\
S3 & 0.65 & 15000 & 2.3 \\
S4 & 0.66 & 4000 & 1.3 \\
\hline
\end{tabular}


Table 8: Contact angles, AFM roughness parameters and fractal analysis data of nontronite clay of size (200x700) nm with respect to the different exchangeable cations. * estimated by extrapolation

\begin{tabular}{l|llllll}
$\begin{array}{l}\text { Exchangeable } \\
\text { cation }\end{array}$ & $\begin{array}{l}\text { Contact } \\
\left({ }^{\circ}\right)\end{array}$ & $\begin{array}{l}\mathrm{RMS} \\
(\mathrm{nm})\end{array}$ & $\begin{array}{l}\mathrm{R}_{\max } \\
(\mathrm{nm})\end{array}$ & $h$ & $\begin{array}{l}\text { Variance at } \\
\text { plateau }\left(\mathrm{nm}^{2}\right)\end{array}$ & $r(\mu \mathrm{m})$ \\
\hline $\mathrm{Na}^{+}$ & 30 & 57 & 370 & 0.69 & 9000 & 1.5 \\
$\mathrm{Li}^{+}$ & 40 & 76 & 412 & 0.69 & 11500 & 1.6 \\
$\mathrm{~K}^{+}$ & 50 & 105 & 534 & 0.71 & 23000 & 2.0 \\
$\mathrm{Ca}^{2+}$ & 21 & 261 & 1263 & 0.60 & $170000^{*}$ & 4.0 \\
\hline
\end{tabular}

